\title{
Associations of 25-Hydroxyvitamin D Levels and Arthritis with Sleep Duration: The Korean National Health and Nutrition Examination Survey 2008-20I4
}

This article was published in the following Dove Press journal:

Nature and Science of Sleep

\author{
Sun-Young $\operatorname{Kim} \mathbb{D I}^{1}$ \\ Mi Hyun Lee ${ }^{2}$ \\ Weon-Jeong Lim' \\ Soo In $\mathrm{Kim}^{3}$ \\ Yu Jin Lee ${ }^{2}$ \\ 'Department of Psychiatry, Ewha \\ Womans University Seoul Hospital, Ewha \\ Womans University College of Medicine, \\ Seoul, Republic of Korea; ${ }^{2}$ Department of \\ Psychiatry and Center for Sleep and \\ Chronobiology, Seoul National University \\ Hospital, Seoul University College of \\ Medicine, Seoul, Republic of Korea; \\ ${ }^{3}$ Department of Psychiatry, Ewha \\ Womans University Mokdong Hospital, \\ Ewha Womans University College of \\ Medicine, Seoul, Republic of Korea
}

Purpose: The mean sleep duration of Koreans is 7 hours 49 minutes, which is the lowest among Organization for Economic Cooperation and Development countries. Although vitamin $\mathrm{D}$ deficiency and arthritis are considered modifiable factors influencing restorative sleep, mean vitamin D levels are low $(17.33 \mathrm{ng} / \mathrm{mL})$ and arthritis is prevalent among Koreans. This study investigated whether vitamin D deficiency and arthritis increase the risk of short sleep duration. Patients and Methods: The current study used data from the Korean National Health and Nutrition Examination Survey (KNHANES) for 46,405 Korean adults. Vitamin D levels were measured using a radioimmunoassay kit. Sleep duration and arthritis history were assessed using a self-reported questionnaire. Sleep duration was categorized as optimal ( 7 to $<9$ hours/day), short ( $<7$ hours/day), and long ( $\geq 9$ hours/day). Vitamin D levels were grouped as vitamin D sufficiency $(\geq 20 \mathrm{ng} / \mathrm{mL})$, insufficiency $(10-19.99 \mathrm{ng} / \mathrm{mL})$, and deficiency $(<10 \mathrm{ng} / \mathrm{mL})$. Multiple imputation was used to compensate for missing data. Multinomial logistic regression was used to examine the associations of vitamin D and arthritis status with sleep duration. The regressions were adjusted for covariates, and each model was adjusted for vitamin D and arthritis.

Results: Among these participants, 23,078 (49.73\%) and 3518 (7.58\%) had short and long sleep duration, respectively; 26,724 (57.59\%) and 4349 (9.37\%) exhibited vitamin D insufficiency and deficiency, respectively; and $4709(10.15 \%)$ were arthritis patients Compared with vitamin D sufficiency, vitamin D insufficiency and deficiency were associated with short sleep duration (vitamin D insufficiency group: $\mathrm{OR}=1.07,95 \% \mathrm{CI}=$ 1.01-1.13; vitamin D deficiency group: $\mathrm{OR}=1.13,95 \% \mathrm{CI}=1.03-1.24)$. The presence of arthritis was associated with short sleep duration $(\mathrm{OR}=1.14,95 \% \mathrm{CI}=1.06-1.22)$ compared with its absence. The interaction between vitamin $\mathrm{D}$ deficiency and the presence of arthritis was significantly associated with short sleep duration. However, long sleep duration was not significantly associated with vitamin D levels or arthritis status.

Conclusion: Low vitamin D levels and the presence of arthritis were associated with an increased risk of short sleep duration. Additionally, there was a positive interaction effect between vitamin $\mathrm{D}$ deficiency and arthritis on short sleep duration.

Keywords: vitamin D, arthritis, sleep duration, Korean National Health and Nutrition Examination Survey, KNHANES

\section{Introduction}

The prevalence of low serum vitamin D levels is increasing. Recent epidemiological studies have reported that the prevalence of a low vitamin $\mathrm{D}$ level, according to
Correspondence: Yu Jin Lee
Department of Psychiatry and Center for Sleep and Chronobiology, Seoul National University Hospital, Seoul National

University College of Medicine, 103

Daehak-Ro, Jongno-Gu, Seoul 03080,

Republic of Korea

Tel +82-2-2072-2456

Fax +82-2-744-724I

Email ewpsyche@snu.ac.kr
Nature and Science of Sleep 2020:12 883-894

sumit your manuscript

(c) (i) (5) $2020 \mathrm{Kim}$ et al. This work is published and licensed by Dove Medical Press Limited. The full terms of this license are available at https://www.dovepress.com/terms.php c. you hereby accept the Terms. Non-commercial uses of the work are permitted without any further permission from Dove Medical Press Limited, provided the work is properly attributed. For permission for commercial use of this work, please see paragraphs 4.2 and 5 of our Terms (https://www.dovepress.com/terms.php). 
a serum 25-hydroxyvitamin D (25(OH)D) cut-off level of $<50 \mathrm{nmol} / \mathrm{L}$, is a global public health problem in all age groups. ${ }^{1}$ In South Korea, the prevalence of vitamin $\mathrm{D}$ deficiency in 2008 was $51.8 \%$ in males and $68.2 \%$ in females. It rose to $75.2 \%$ and $82.5 \%$, respectively, in 2014 . $^{2}$ A range of studies have reported that vitamin D deficiency is associated not only with chronic medical illnesses (cardiovascular disease, asthma, autoimmune disease, and cancer) ${ }^{3-6}$ but also with psychiatric disorders (depressive disorders, autistic spectrum disorder, neurocognitive disorders, and psychotic disorders). ${ }^{7}$ As the vitamin $\mathrm{D}$ receptor is widely distributed throughout various tissues including brain tissues, the potential role of vitamin $\mathrm{D}$ as a neurosteroid has become of interest. Vitamin D has been reported to bind in several areas in the brain such as the anterior and posterior hypothalamus, substantia nigra, midbrain central grey matter, raphe nuclei, and in the nucleus reticularis pontis oralis and caudalis, which have roles in sleep regulation. Furthermore, vitamin D plays a pivotal role in the synthesis of serotonin and melatonin. ${ }^{8}$ Previous studies have shown that short sleep duration is associated with increased mortality, diabetes mellitus, hypertension, cardiovascular diseases, coronary heart diseases, and obesity. ${ }^{9}$ In addition, Han et al reported that $14.22 \%$ of those studied had short sleep duration ( $<6$ hours/day), which may be a public health concern in South Korea. ${ }^{10}$ Thus, some studies have addressed the relationship between sleep and vitamin D levels. According to a systematic review and meta-analysis, a low vitamin D concentration may be associated with sleep disorders. ${ }^{11}$ However, some of these studies had methodological limitations, such as a relatively small sample size, included only specific subgroups of the population, and omitted crucial confounding factors, such as body mass index (BMI), physical activity, depression, medical conditions related to the vitamin D level, and sleep. Therefore, it is necessary to analyze the relationship between vitamin $\mathrm{D}$ levels and sleep in a large sample that includes various covariates.

In terms of the relationship between arthritis and sleep, many studies have determined that arthritis increases the risk of sleep disturbance. According to a current meta-analysis, the pooled prevalence of sleep disorders among arthritis patients was $44 \%$, making it the most prevalent comorbidity. ${ }^{12}$ Considering that the arthritis prevalence was above $35 \%$ in South Korea, sleep disturbance due to pain or inflammation derived from arthritis is problematic. ${ }^{13,14}$ Meanwhile, vitamin D plays a central role in bone and cartilage metabolism and pain management, through beneficial effects on inflammation and neurotransmitters; ${ }^{15,16}$ vitamin D deficiency is associated with arthritis, which negatively affects sleep. Therefore, considering that vitamin $\mathrm{D}$, arthritis, and sleep may be interrelated, the relationship among vitamin $\mathrm{D}$, arthritis, and sleep needs to be investigated. In addition, given that South Korea is already an aged society and older people are more vulnerable to vitamin D deficiency and arthritis, we should pay attention to modifiable factors that cause sleep disturbance.

Based on this background, the present study examined the associations of vitamin D levels and the presence of arthritis (ie, osteoarthritis or rheumatoid arthritis; OA or RA) with sleep duration in a nationally representative sample. Our hypotheses were as follows. First, short sleep duration may be negatively associated with vitamin D levels and positively associated with arthritis. Considering that low vitamin D levels are associated with arthritis, we examined whether vitamin D and arthritis influenced the other's association with short sleep duration by adjusting them individually in the final models. Second, the interaction between vitamin D levels and the presence of arthritis may be associated with short sleep duration. Third, long sleep duration may not be associated with vitamin D levels or arthritis status.

\section{Patients and Methods \\ Study Population}

This study used data collected from the Korean National Health and Nutrition Examination Survey (KNHANES), which is a nationally representative, cross-sectional survey that has been conducted annually by the Korea Centers for Disease Control and Prevention (KCDC) since 1998. ${ }^{17}$ The participants in the KNHANES were selected using a complex, stratified, multi-stage cluster sampling design among non-institutionalized civilians from the South Korean population. The response rate for those who were contacted was $76.5-82.8 \%$. The health interview and health examination were performed by trained medical staff and interviewers in mobile examination centers. Professional interviewers included nurses, dietitians, and health science graduates, who interviewed participants about their health in person. The health examination included blood and urine collection, anthropometry, and muscle strength testing. Self-reported data regarding sociodemographic characteristics, such as age, sex, marital status, education level, income, alcohol consumption, smoking status, amount of physical activity, sleep duration, quality of life, and personal medical history were 
collected during the health interview. Anthropometric and blood biochemical data were measured during the health examination. To reduce non-sampling errors, the KCDC employs the following strategies: periodic staff training and monitoring by external experts; provision of feedback; use of certified examiners and a standardized laboratory environment; regular calibration of equipment; and regular reviews of findings. All samples are analyzed by a certified laboratory. A laboratory data quality control program is used to ensure precision and accuracy. ${ }^{17}$ All participants provided written informed consent, and the survey protocol was approved by the KCDC Institutional Review Board (IRB Nos. 2008-04EXP-01-C, 2009-01CON-032C， 2010-02CON-21-C, 2011-02CON-06-C, 2012 01EXP-01-2C, 2013-07OCN-03-4C, and 2013-12EXP03-5C).

The current study used a cross-sectional design of 53,410 subjects aged 18-80 years who had participated in the KNHANES between January 2008 and December 2014. Considering the possibility of reverse causation, data were used to select participants with no evidence of a psychiatric disorder or physical illness. To evaluate medical history, participants were asked whether they had ever been diagnosed with any disease by a medical doctor before the survey. First, those who had been diagnosed with a depressive disorder were excluded because there is increasing evidence that vitamin $\mathrm{D}$ deficiency is associated with depressive disorders, which cause sleep disturbances $(\mathrm{N}=1998){ }^{7}$ Second, individuals who had been diagnosed with a chronic medical illness by a medical doctor were excluded (cerebral infarction, myocardial infarction/angina, asthma, thyroid disease, and cancer). In addition, we excluded participants who had liver and/or chronic renal disease, as vitamin $\mathrm{D}_{2}$ and $\mathrm{D}_{3}$ are hydroxylated twice in the liver and the kidneys to initiate their metabolic activity. ${ }^{7}$ If arthritis patients reported the aforementioned psychiatric disorders or medical illnesses, we also excluded them $(\mathrm{N}=5429)$. Several subjects met more than one exclusion criterion. The total number of subjects eligible for this study was 46,405 (Figure 1).

\section{Study Variables and Measurements Assessment of 25(OH)D Levels}

Blood specimens were collected after an 8-hour fast and were centrifuged to isolate the serum. The concentration of 25 $(\mathrm{OH}) \mathrm{D}$, with equimolar measurements of $25(\mathrm{OH}) \mathrm{D}_{2}$ and $25(\mathrm{OH}) \mathrm{D}_{3}$, which is a marker of vitamin $\mathrm{D}$ status, was measured using a radioimmunoassay kit (DiaSorin, Stillwater, MN, USA) using the 1470 WIZARD gammaCounter (PerkinElmer, Turku, Finland). The KCDC continuously monitored and checked 25(OH)D levels via internal and external quality control. Internal quality control, using the Westgard multi-rule control method, is performed to evaluate the precision and accuracy of an analytical system using mean, standard deviation (SD), and coefficient of variation (\%) values. The coefficient of variation for the control material was $<7.6 \%$ for the low level and $<5.8 \%$ for the high level. External quality control was evaluated using the Vitamin D Quality Assessment Scheme, Vitamin D Metabolites Quality Assurance Program of the National Institute of Standards and Technology, Accuracy-based Vitamin D Survey of College of American Pathologists. ${ }^{17}$ The participants were divided into the following three categories according to their $25(\mathrm{OH}) \mathrm{D}$ concentration based on established definitions and practical guidelines: vitamin D deficient $(<10 \mathrm{ng} / \mathrm{mL})$, insufficient $(10-19.99 \mathrm{ng} / \mathrm{mL})$, and sufficient $(\geq 20 \mathrm{ng} / \mathrm{mL}){ }^{18,19}$

\section{Assessment of Arthritis}

To identify patients with arthritis, participants were asked a yes-or-no question of whether they had ever been diagnosed with OA or RA by a medical doctor.

\section{Assessment of Sleep Duration}

Participants were asked how many hours they usually slept at night ("How many hours do you usually sleep a day?"). Based on a joint consensus statement of the American Academy of Sleep Medicine and Sleep Research Society, the participants were divided into the following three categories according to their total sleep time: short $(<7$ hours/day), optimal (7 to $<9$ hours/day), and long ( $\geq 9$ hours/day) sleep duration. ${ }^{20}$

\section{Covariates}

Information about age, sex, marital status, education and income levels, alcohol consumption frequency, smoking status, amount of physical activity, and anxiety/depressive symptoms were collected via self-reported questionnaires. Marital status was classified as never married, married, or other. Education level was categorized as elementary school or less, middle school, high school diploma, or college degree or higher. Income was classified as 1st quartile (low), 2nd quartile (low-middle), 3rd quartile (middle-high), or 4th quartile (high) using standard income quartiles of the sample. Alcohol consumption frequency was classified as $\leq 1$ time/month, 2-4 times/month, 2-3 


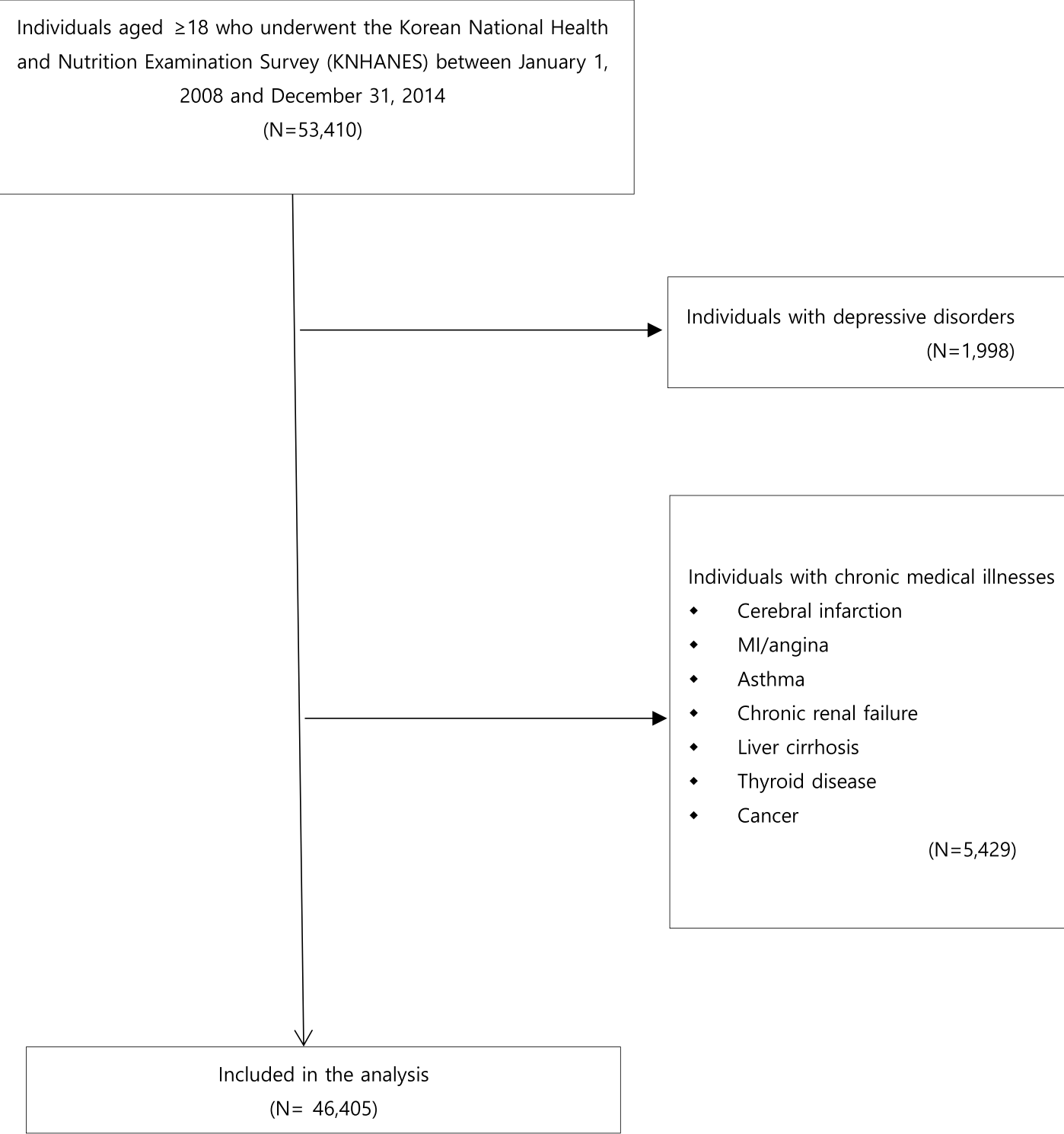

Figure I Overview of the study participant selection.

times/week, or $\geq 4$ times/week. Smoking status was classified as never smoker, former smoker, or current smoker.

The amount of physical activity was measured using the International Physical Activity Questionnaire short form. Physical activity energy expenditure was estimated using metabolic equivalent tasks (METs). Absolute MET values were assigned for walking, moderate intensity exercise, and vigorous intensity exercise (3.3, 4.0, and 8.0 METs, respectively). The amount of weekly physical activity at each intensity level was calculated by multiplying the minutes spent at a specific intensity per week by the absolute MET values assigned to each category of physical activity intensity. Energy expended per week at all three physical activity intensity levels was summed to calculate the total energy expended. ${ }^{21}$ Physical inactivity decreases the opportunity for exposure to sunlight and increases arthritis pain, severity, and related disability. ${ }^{22}$ Therefore, the amount of physical activity was included as a covariate.

The level of anxiety/depressive symptoms was measured using the anxiety/depression items on the EuroQoL-5D-3L instrument. Although we excluded subjects with a depressive disorder, some clinically depressed participants may not have received treatment; therefore, the level of anxiety/depressive symptoms was included as a covariate.

BMI was calculated by dividing weight $(\mathrm{kg})$ by height squared $\left(\mathrm{m}^{2}\right)$. Studies have suggested a bidirectional relationship between vitamin $\mathrm{D}$ deficiency and obesity. ${ }^{23}$ 
Additionally, current systematic reviews have reported that obesity negatively affects arthritis by increasing proinflammatory cytokine levels. ${ }^{24,25}$ Therefore, we controlled for BMI in our analyses.

\section{Statistical Analysis}

Multiple imputation was used to allow for uncertainty about the missing data by creating 10 different plausible imputed data sets and appropriately combining results obtained from each of them. Descriptive statistics were used to display the baseline characteristics according to sleep duration. ANOVA and chi-square tests were used to identify differences among subjects sleeping $<7$ hours/day, 7 to $<9$ hours/day, and $\geq 9$ hours/day. To determine whether vitamin D levels and the presence of arthritis were associated with sleep duration, we used regression models. Logistic regression was used to calculate the odds ratios (ORs) for short ( $<7$ hours/day) and long ( $\geq 9$ hours/day) sleep duration according to vitamin D status (sufficient: $\geq 20 \mathrm{ng} / \mathrm{mL}$, insufficient: $10-19.99 \mathrm{ng} / \mathrm{mL}$, deficient: $<10$ $\mathrm{ng} / \mathrm{mL}$ ) or presence of arthritis (OA or RA). All regression models were adjusted for age, sex, marital status, education and income level, alcohol consumption frequency, smoking status, amount of physical activity, BMI, and anxiety/depressive symptoms sequentially. First, we analyzed crude logistic regression models without adjustment (Model 0). Second, because older people are more vulnerable to vitamin D deficiency and arthritis, we adjusted for age (Model 1). Third, we added sex, sociodemographic factors, anthropometric factors, and amount of physical activity as covariates (Model 2). Fourth, although we excluded those who had depressive disorders because baseline anxiety/depressive symptoms affect sleep duration, we adjusted for anxiety/depressive symptoms (Model 3). Finally, the logistic regression models were mutually adjusted for the serum vitamin D level and presence of arthritis to examine whether each affected the other's relationship with short sleep duration (Model 4). Interactions between the serum vitamin $\mathrm{D}$ level and presence of arthritis were also examined. The statistical analyses were performed using STATA version 14.0 (StataCorp LLC., College Station, TX, USA). A twotailed p-value $<0.05$ was considered significant.

\section{Results}

Table 1 displays participant characteristics. Among the 46,405 participants, 23,078 (49.73\%) slept $<7$ hours/day, $19,809(42.69 \%)$ slept 7 to $<9$ hours/day, and 3518
(7.58\%) slept $\geq 9$ hours/day. Those belonging to the vitamin D sufficiency, insufficiency, deficiency groups comprised 15,332 (33.04\%), 26,724 (57.59\%), and 4349 (9.37\%) participants, respectively; 4709 (10.15\%) subjects had arthritis. The mean ages of the participants who slept $<7$ hours/day, 7 to $<9$ hours/day, and $\geq 9$ hours/day were $46.57 \pm 0.11$ years, $50.55 \pm 0.12$ years, and $48.19 \pm 0.35$ years, respectively; the differences among the three groups were significant. Compared with participants who slept 7 to $<9$ hours/day, those who slept $<7$ hours/day or $\geq 9$ hours/day were more likely to be younger, women, never married, non-smokers, and to have lower BMI and lower rates of more than moderate anxiety/depressive symptoms. Compared with participants who slept 7 to $<9$ hours/day, those who slept $<7$ hours/day had more education, higher income levels, and lower alcohol consumption frequency. Participants who slept $\geq 9$ hours/day had less education, lower income, and higher alcohol consumption frequency. Differences were observed in the proportion of subjects with vitamin D sufficiency, insufficiency, or deficiency among the groups who slept $<7$ hours/day (9.32\%), 7 to $<9$ hours/day $(9.23 \%)$, and $\geq 9$ hours/day $(10.49 \%)(\mathrm{p}=$ 0.017). The proportions of individuals with and without arthritis differed among groups who slept $<7$ hours/day $(8.18 \%), 7$ to $<9$ hours/day $(12.26 \%)$, and those who slept $\geq 9$ hours/day $(11.17 \%)(\mathrm{p}<0.001)$.

Table 2 shows the association of serum vitamin D levels and the presence of arthritis with sleep duration after adjustment for all covariates. Higher levels of vitamin D were significantly associated with longer sleep duration: for every 10 $\mathrm{ng} / \mathrm{mL}$ increase in vitamin $\mathrm{D}$ level, sleep duration increased by 3.6 minutes $(\beta=0.006,95 \% \mathrm{Cl}=0.003-0.008)$. Meanwhile, compared with no arthritis history, the presence of arthritis was associated with shorter sleep duration $(\beta=-0.161,95 \%$ $\mathrm{Cl}=-0.207$ to -0.116 ).

Table 3 shows the association between serum vitamin D status and short/long sleep duration after adjusting for various covariates. In the crude model, neither vitamin D insufficiency nor vitamin D deficiency were associated with the risk of short sleep duration (Model 0, vitamin D insufficiency: $\mathrm{OR}=0.96,95 \% \mathrm{CI}=0.92-1.01$; vitamin $\mathrm{D}$ deficiency: $\mathrm{OR}=0.98,95 \% \mathrm{CI}=0.90-1.07$ ). However, after adjusting for age, the difference was significant (Model 1, vitamin D insufficiency: OR $=1.06,95 \%$ $\mathrm{CI}=1.01-1.12$; vitamin $\mathrm{D}$ deficiency: $\mathrm{OR}=1.13,95 \%$ $\mathrm{CI}=1.04-1.23)$. There was little difference in the OR for short sleep duration before versus after adjusting for arthritis (Model 3 vs Model 4). In the final model adjusted for all 
Table I Sociodemographic Characteristics of the Participants According to Sleep Duration

\begin{tabular}{|c|c|c|c|c|}
\hline & \multicolumn{4}{|c|}{ Sleep duration (hours/day) } \\
\hline & $\begin{array}{l}<7 \text { hours } \\
(n=23,078)\end{array}$ & $\begin{array}{l}7 \text { to }<9 \text { hours } \\
(n=19,809)\end{array}$ & $\begin{array}{l}\geq 9 \text { hours } \\
(n=3,518)\end{array}$ & \multirow[t]{2}{*}{$P$} \\
\hline & \multicolumn{3}{|c|}{ Mean \pm SD or $n(\%)$} & \\
\hline Age & $46.57 \pm 0.11$ & $50.55 \pm 0.12$ & $48.19 \pm 0.35$ & $<0.001$ \\
\hline $\begin{array}{l}\text { Sex } \\
\qquad \text { Men } \\
\text { Women }\end{array}$ & $\begin{array}{l}10,510(45.54) \\
12,568(54.46)\end{array}$ & $\begin{array}{l}9,046(45.67) \\
10,763(54.33)\end{array}$ & $\begin{array}{l}\mathrm{I}, 454(4 \mathrm{I} .33) \\
2,064(58.67)\end{array}$ & $<0.001$ \\
\hline $\begin{array}{l}\text { Marital status } \\
\text { Married } \\
\text { Never married } \\
\text { Other }\end{array}$ & $\begin{array}{l}18,939(82.07) \\
4,080(17.68) \\
59(0.26)\end{array}$ & $\begin{array}{l}16,800(84.81) \\
2,935(14.82) \\
74(0.37)\end{array}$ & $\begin{array}{l}2,703(76.83) \\
801(22.77) \\
14(0.40)\end{array}$ & $<0.001$ \\
\hline $\begin{array}{l}\text { Education } \\
\text { Elementary school or less } \\
\text { Middle school } \\
\text { High school diploma } \\
\text { College degree or higher }\end{array}$ & $\begin{array}{l}4,423(19.17) \\
2,370(10.27) \\
8,532(36.97) \\
7,753(33.59)\end{array}$ & $\begin{array}{l}5,394(27.23) \\
2,264(11.43) \\
6,576(33.20) \\
5,575(28.14)\end{array}$ & $\begin{array}{l}1,116(31.72) \\
389(11.06) \\
1,232(35.02) \\
781(22.20)\end{array}$ & $<0.001$ \\
\hline $\begin{array}{l}\text { Income } \\
\qquad 1^{\text {st }} \text { quartile (low) } \\
2^{\text {nd }} \text { quartile (low-middle) } \\
3^{\text {rd }} \text { quartile (middle-high) } \\
4^{\text {th }} \text { quartile (high) }\end{array}$ & $\begin{array}{l}5,520(23.92) \\
5,819(25.21) \\
5,799(25.13) \\
5,940(25.74)\end{array}$ & $\begin{array}{l}4,929(24.88) \\
4,902(24.75) \\
4,977(25.12) \\
5,001(25.25)\end{array}$ & $\begin{array}{l}1,020(28.99) \\
943(26.81) \\
839(23.85) \\
716(20.35)\end{array}$ & $<0.001$ \\
\hline $\begin{array}{l}\text { Alcohol consumption frequency } \\
\leq 1 \text { time/month } \\
2-4 \text { times/month } \\
2-3 \text { times/week } \\
\geq 4 \text { times/week }\end{array}$ & $\begin{array}{l}8,823(38.23) \\
8,857(38.38) \\
3,765(16.31) \\
1,633(7.08)\end{array}$ & $\begin{array}{l}7,627(38.50) \\
7,154(36.11) \\
3,361(16.97) \\
1,667(8.42)\end{array}$ & $\begin{array}{l}1,509(42.89) \\
1,216(34.57) \\
493(14.01) \\
300(8.53)\end{array}$ & $<0.001$ \\
\hline $\begin{array}{l}\text { Smoking status } \\
\text { Never smoker } \\
\text { Former smoker } \\
\text { Current smoker }\end{array}$ & $\begin{array}{l}13,496(58.48) \\
3,169(13.73) \\
6,413(27.79)\end{array}$ & $\begin{array}{l}\text { II,487 (57.99) } \\
2,774(14.00) \\
5,548(28.01)\end{array}$ & $\begin{array}{l}2,067(58.75) \\
437(12.42) \\
1,014(28.82)\end{array}$ & 0.124 \\
\hline $\begin{array}{l}\text { Amount of physical activity } \\
\text { (MET-min/week) }\end{array}$ & $3033.25 \pm 37.10$ & $3127.95 \pm 37.18$ & $2896.54 \pm 86.00$ & 0.874 \\
\hline BMI & $23.47 \pm 0.02$ & $23.82 \pm 0.02$ & $23.15 \pm 0.07$ & 0.007 \\
\hline $\begin{array}{l}\text { Anxiety /depressive symptoms } \\
\text { (EQ-5D-3L) } \\
\text { Not anxious or depressed } \\
\text { Moderately anxious or depressed } \\
\text { Extremely anxious or depressed }\end{array}$ & $\begin{array}{l}21,158(91.68) \\
1,811(7.85) \\
109(0.47)\end{array}$ & $\begin{array}{l}17,392(87.80) \\
2,249(11.35) \\
168(0.85)\end{array}$ & $\begin{array}{l}3,097(88.03) \\
385(10.94) \\
36(1.02)\end{array}$ & $<0.001$ \\
\hline $\begin{array}{l}\text { Vitamin } D(25(\mathrm{OH}) \mathrm{D}) \text { level } \\
\text { Sufficiency, } \geq 20 \mathrm{ng} / \mathrm{mL} \\
\text { Insufficiency, } 10-19.99 \mathrm{ng} / \mathrm{mL} \\
\text { Deficiency, }<10 \mathrm{ng} / \mathrm{mL}\end{array}$ & $\begin{array}{l}7,525(32.61) \\
13,402(58.07) \\
2,151(9.32)\end{array}$ & $\begin{array}{l}6,609(33.36) \\
\text { II,37। }(57.40) \\
I, 829(9.23)\end{array}$ & $\begin{array}{l}\text { I, } 198 \text { (34.05) } \\
\text { I,95I (55.46) } \\
369(10.49)\end{array}$ & 0.017 \\
\hline $\begin{array}{c}\text { Arthritis } \\
\text { No } \\
\text { Yes }\end{array}$ & $\begin{array}{l}21,190(91.82) \\
1,888(8.18)\end{array}$ & $\begin{array}{l}|7,38|(87.74) \\
2,428(12.26)\end{array}$ & $\begin{array}{l}3,125(88.83) \\
393(11.17)\end{array}$ & $<0.001$ \\
\hline
\end{tabular}

Abbreviations: BMI, body mass index; EQ-5-3L, EuroQoL-5D-3. 
Table 2 Association of Vitamin D $(25(\mathrm{OH}) \mathrm{D})$ and Arthritis Presence with Sleep Duration

\begin{tabular}{|l|l|l|}
\hline \multirow{2}{*}{} & \multicolumn{2}{|l|}{ Sleep Duration (Hours/Day) } \\
\cline { 2 - 3 } & $\boldsymbol{\beta}(95 \% \mathrm{Cl})$ & p-value \\
\hline Vitamin D (25(OH)D) level $(\mathrm{ng} / \mathrm{mL})^{\mathrm{a}}$ & $0.006(0.003,0.008)$ & $<0.00 \mathrm{I}$ \\
\hline $\begin{array}{l}\text { Presence of arthritis (RA or OA) } \\
\text { No } \\
\text { Yes }\end{array}$ & $\begin{array}{l}\text { I [Reference }] \\
-0.16 \mathrm{I}(-0.207,-0.116)\end{array}$ & $<0.00 \mathrm{I}$ \\
\hline
\end{tabular}

Notes: $\beta=$ standardized regression coefficient. ${ }^{\text {a} A d j u s t e d ~ f o r ~ a g e, ~ s e x, ~ m a r i t a l ~}$ status, education, income, alcohol consumption frequency, smoking status, amount of physical activity, BMI, anxiety/depressive symptoms, and arthritis history ${ }^{b}$ Adjusted for age, sex, marital status, education, income, alcohol consumption frequency, smoking status, amount of physical activity, BMI, anxiety/depressive symptoms, and vitamin $D$ levels.

Abbreviations: OA, osteoarthritis; RA, rheumatoid arthritis.

covariates, those with vitamin D insufficiency (10-19.99 $\mathrm{ng} / \mathrm{mL} 25(\mathrm{OH}) \mathrm{D})$ and deficiency $(<10 \mathrm{ng} / \mathrm{mL} 25(\mathrm{OH}) \mathrm{D})$ had $7 \%(\mathrm{OR}=1.07,95 \% \mathrm{CI}=1.01-1.13)$ and $13 \%(\mathrm{OR}=1.13$, $95 \% \mathrm{CI}=1.03-1.24)$ increased odds of short sleep duration compared to those exhibiting vitamin D sufficiency $(\geq 20$ $\mathrm{ng} / \mathrm{mL} 25(\mathrm{OH}) \mathrm{D})$. However, there was no significant association between vitamin $\mathrm{D}$ levels and long sleep duration.

Table 4 shows the association between arthritis history and short/long sleep duration in the study population. There was little difference in the OR for short sleep duration before and after adjusting for the serum vitamin $\mathrm{D}$ level (Model 3 vs Model 4). After adjusting for all confounding variables, those with an OA history had a $14 \%(\mathrm{OR}=1.14$, 95\% CI $=1.06-1.22)$ increased odds of short sleep duration, compared with those who did not have an arthritis history. However, there was no significant association between arthritis and long sleep duration.

Although there was no interaction between arthritis and vitamin D on long sleep duration, moderating effects of arthritis between vitamin D and short sleep duration were observed $(p=0.007)$. Table 5 shows the results of logistic regression analyses of the association between serum vitamin D level and short sleep duration ( $<7$ hours/day) in adults with/without arthritis. The OR of vitamin $\mathrm{D}$ deficiency groups for short sleep duration was higher in those with than in those without arthritis (with arthritis: $\mathrm{OR}=1.46,95 \% \mathrm{CI}=1.11-1.92$; without arthritis: $\mathrm{OR}=$ $1.12,95 \% \mathrm{CI}=1.01-1.25$ ) (Figure 2 ).

\section{Discussion}

The results of this study showed that low vitamin D levels $(<20 \mathrm{ng} / \mathrm{mL} 25(\mathrm{OH}) \mathrm{D})$ and the presence of arthritis were associated with short sleep duration $(<7$ hours/day). In addition, there was a positive interaction between vitamin D deficiency and the presence of arthritis in the association of vitamin D deficiency with short sleep duration ( $<7$ hours/day). However, the results of this study showed that vitamin D levels and the presence of arthritis were not associated with long sleep duration.

When we adjusted sequentially for a range of covariates in the association between vitamin D levels and short sleep duration ( $<7$ hours/day), age was influential in reversing the association between vitamin D levels and short sleep duration. Previous studies have reported that, with aging, individuals lose the function of vitamin $\mathrm{D}$ photosynthesis due to high skin melanin content. ${ }^{1}$ Moreover, UVB exposure decreases because the amount of physical activity tends to decrease. ${ }^{26}$ Finally, sleep duration tends to decrease with aging. ${ }^{27}$

In a multi-ethnic study using data from a communitybased cohort of six US field centers, Bertisch et $\mathrm{al}^{28}$ reported that the vitamin D-deficient group slept an average of 13.0 minutes less than the vitamin D-sufficient group after adjusting for demographics, obesity, and health habits, which was consistent with our results. Several plausible mechanisms have been suggested for the relationship between vitamin D deficiency and short sleep duration. First, there is evidence of the expression of the vitamin D receptor and $1 \alpha$-hydroxylase in specific cortical and subcortical areas involved in sleep, such as the prefrontal cortex, substantia nigra, and hypothalamus. ${ }^{29}$ The prefrontal cortex mediates normal sleep physiology and sleep deprivation phenomena duration non-rapid eye movement (NREM) and rapid eye movement (REM) sleep. $^{30}$ The substantia nigra is involved in regulating the sleep-wake cycle. ${ }^{31}$ The anterior hypothalamus, including the supraoptic and paraventricular nuclei receives efferent neural pathways from the ventrolateral preoptic nucleus, which plays an important role in the regulation of NREM and REM sleep. ${ }^{32,33}$ Because vitamin D modulates neuronal excitability and upregulates the synthesis of neurotrophins, the brain region related to sleep may be affected by the vitamin D level.

Second, vitamin D has a suppressive role in autoimmunity and an anti-inflammatory effect, which affects the regulation and modulation of sleep. ${ }^{34}$ Direct neural communication from the peripheral immune system to the central nervous system occurs via the vagus nerve. Vagal afferents project to brain stem nuclei, including the nucleus of the solitary tract, ventrolateral medulla, 


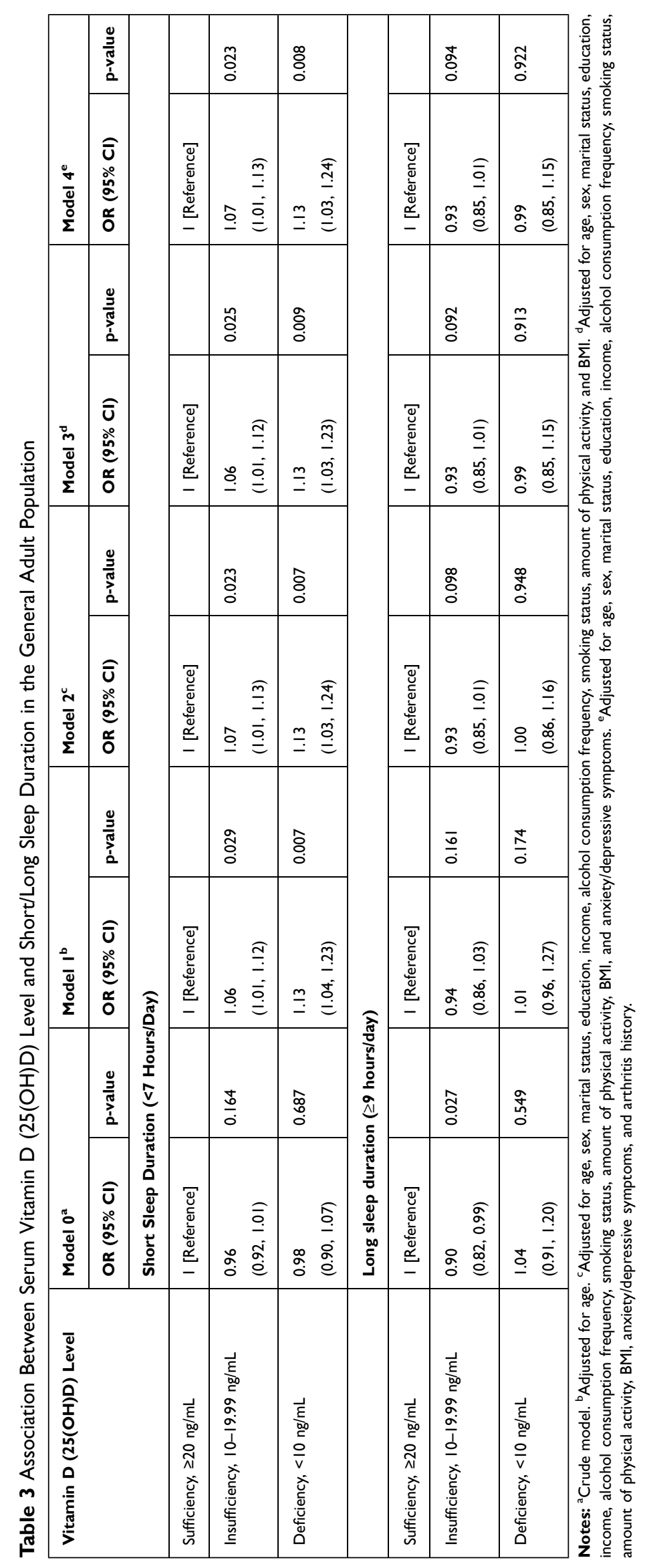




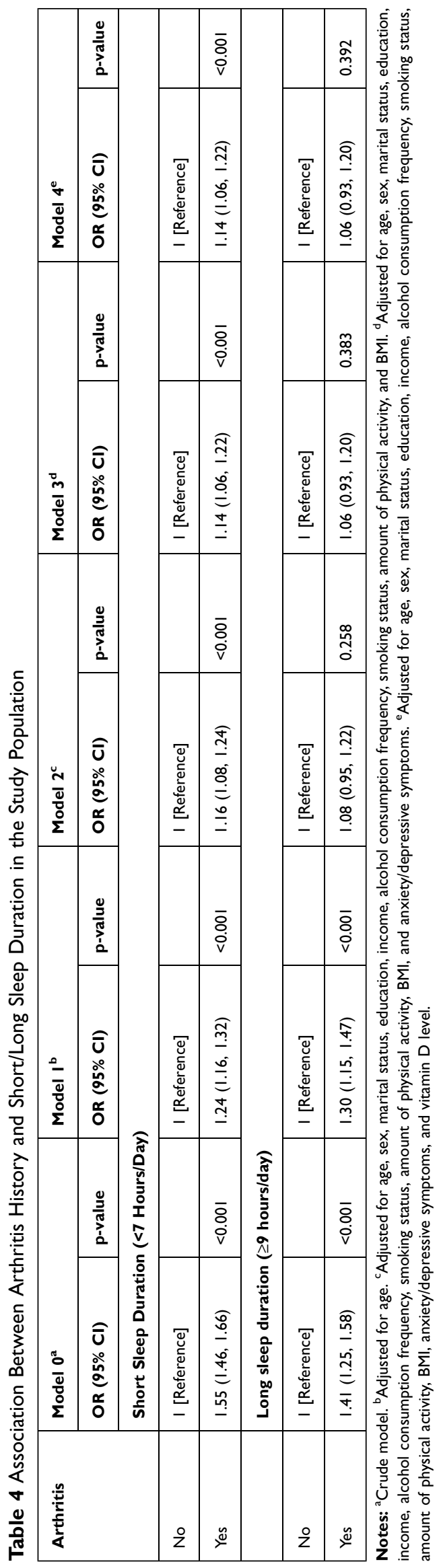

paraventricular and supraoptic nuclei of the hypothalamus, and amygdala, which is involved in the regulation and modulation of sleep. ${ }^{35}$ In addition, pro-inflammatory cytokines enter the brain by volume diffusion and active transportation across the blood-brain barrier, which is likely an important contributor to changes in sleep occurring during an infection. ${ }^{34}$ Therefore, the immunomodulatory effects of vitamin D are associated with normalizing sleep duration.

Third, there is evidence that vitamin D contributes to regulating serotonin synthesis via transcriptional activation of tryptophan hydroxylase 2 . In addition, serotonin produces the sleep hormone melatonin. ${ }^{36}$

In terms of the relationship between vitamin D levels and long sleep duration, the results of our study showed no significant association. Previous studies have examined an association between vitamin D deficiency and various sleep disorders related to long sleep duration such as narcolepsy and obstructive sleep apnea, although the results were inconsistent. Dauvilliers et $\mathrm{al}^{37}$ showed that vitamin D levels were not associated with type 1 narcolepsy in a large case-control study. However, a systematic review and meta-analysis found relative insufficiency in serum 25(OH)D levels among obstructive sleep apnea patients compared to control patients, which was incrementally exacerbated with increasing severity of sleep apnea. ${ }^{38}$ McCarty et $\mathrm{al}^{39}$ reported that sleepiness was inversely correlated with vitamin D concentration in a vitamin D-sufficient group. However, in vitamin D-deficient groups, sleepiness was directly correlated with vitamin D levels in black, but not white participants. Therefore, future studies should consider ethnic differences and previous sleep disorders such as narcolepsy and obstructive sleep apnea in analyzing the relationship of vitamin D level and long sleep duration.

Consistent with previous studies, our results indicate that the presence of arthritis (OA or RA) increased the risk of short sleep duration ( $<7$ hours/day). Mechanisms of this association have been suggested, such as pain-related alertness, release of cytokines, and depression. ${ }^{40,41}$ A previous study reported significant associations between arthritis and long sleep duration, which conflicts with the current results. Kim et $\mathrm{al}^{40}$ reported a higher prevalence of long sleep duration ( $\geq 9$ hours/day) in RA patients, likely to be due to fatigue resulting from systematic inflammation, sleep apnea due to physical inactivity, and comorbid medical illnesses. Since our study excluded arthritis patients with comorbid chronic medical illnesses and adjusted for BMI and the amount of physical activity, the association 
Table 5 Multivariate Logistic Regression Analyses of the Association Between the Serum Vitamin D $(25(\mathrm{OH}) \mathrm{D})$ Level and Short Sleep Duration (<7 Hours/Day) in Adults with/without Arthritis

\begin{tabular}{|l|l|l|}
\hline Vitamin D (25(OH)D) Level & OR $^{\mathbf{a}} \mathbf{( 9 5 \% ~ C I )}$ & p-value \\
\hline Without arthritis & & \\
Sufficiency, $\geq 20 \mathrm{ng} / \mathrm{mL}$ & I [Reference] & \\
Insufficiency, $10-19.99 \mathrm{ng} / \mathrm{mL}$ & I.06 (I.0I, I.I2) & 0.029 \\
Deficiency, $<10 \mathrm{ng} / \mathrm{mL}$ & I.I2(I.0I, I.25) & 0.034 \\
\hline With arthritis & & \\
Sufficiency, $\geq 20 \mathrm{ng} / \mathrm{mL}$ & I [Reference] & \\
Insufficiency, $10-19.99 \mathrm{ng} / \mathrm{mL}$ & I.I0 (0.97, I.27) & 0.140 \\
Deficiency, $<10 \mathrm{ng} / \mathrm{mL}$ & I.46 (I.II, I.92) & 0.007 \\
\hline
\end{tabular}

Notes: ${ }^{2}$ Adjusted for age, sex, marital status, education, income, alcohol consumption frequency, smoking status, amount of physical activity, BMI, and anxiety/depressive symptoms.

between arthritis and long sleep duration can lose significance. Another thing to consider is that we did not control for sleep apnea; future studies should include sleep apnea as a covariate to analyze the association between arthritis and long sleep duration more precisely.

The results of the present study show that there was a positive interaction between vitamin $\mathrm{D}$ and arthritis in the association of vitamin D deficiency with short sleep duration (Figure 2). Considering that serotonin plays a role in reducing pain sensation and depressive symptoms, a low vitamin D concentration results in decreased synthesis of serotonin, which may aggravate pain and increase the risk of short sleep duration. ${ }^{7,8}$ Given that vitamin D regulates and suppresses pro-inflammatory cytokines, patients with arthritis and vitamin D deficiency can have increased inflammation, influencing various brain regions involved in sleep regulation. ${ }^{34}$

The results of this study should be interpreted with caution because of several potential limitations. First, as the study design was cross-sectional, inflated associations and reverse causality are possible. Second, as this study assessed sleep duration and arthritis history based on a selfreported questionnaire, the results could be affected by response bias. Third, this study included only sleep duration as a dependent variable; however, as various parameters are used to evaluate sleep quality, such as sleep efficiency, a future study including additional sleep-related parameters is needed. Fourth, we did not adjust for the season in which the participants were enrolled. In addition, although we adjusted for the amount of physical activity, it is unclear whether this activity was performed outdoors or indoors. Because vitamin D levels depend on the duration of sun exposure, information about the season when data were collected should be acquired and included as a covariate. Fifth, although we excluded patients with a range of chronic diseases, individuals who took steroids or had steroidinduced diabetes could not be excluded because no information related to steroid use was collected. Sixth, given that the KNHANES dataset also did not provide any information on psychiatric medications that might affect sleep, such as benzodiazepine, z-drugs, or sedative antidepressants, we did not exclude or adjust them in our analyses. A future study should include information about steroids and psychiatric medications as a covariate. Seventh, we had no information about whether the participants consumed vitamin D supplements; because vitamin D supplementation

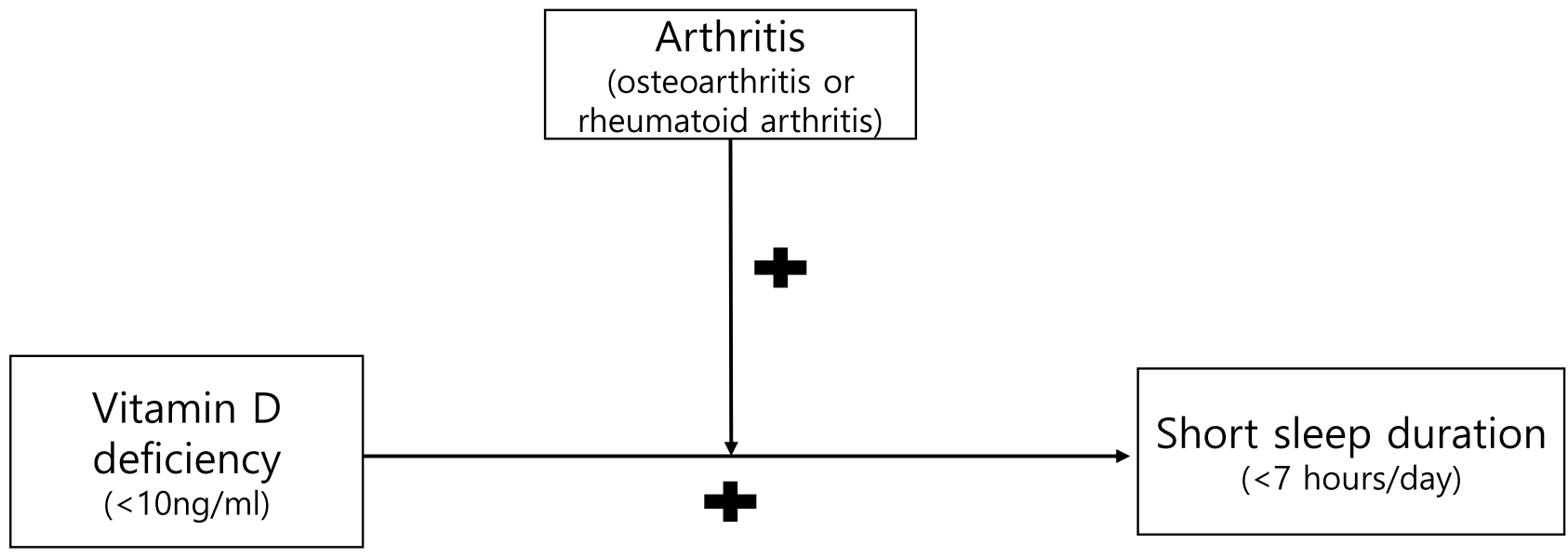

Figure 2 Moderating effect of arthritis on the relationship between vitamin $D$ deficiency and short sleep duration. There was a positive interaction between vitamin $D$ deficiency $(<10 \mathrm{ng} / \mathrm{mL})$ and arthritis on the risk of short sleep duration $(<7$ hours/day) $(p=0.007)$. When data were stratified by the presence of arthritis, the odds ratio of vitamin D deficiency groups for short sleep duration were higher in those with arthritis than in those without arthritis. A conceptual model displays moderating effects of arthritis on the relationship between vitamin D deficiency and short sleep duration. 
reflects health-seeking behaviors and/or motivation, sleep duration and quality may differ according to how individuals achieve a sufficient vitamin D level. Eighth, arthritis comprises various diseases with different etiologies; we included only RA and OA in the arthritis variable and did not consider other forms of arthritis. In addition, we did not stratify arthritis data by RA and OA. However, in terms of the relationship between arthritis and sleep, we have focused on pain and inflammation; pain causes arousal and sleep fragmentation, and inflammation due to arthritis is related to various neurotransmitters that induce and maintain sleep. Ninth, the KNHANES dataset also did not provide any information on the length of arthritis diagnoses. Given the longer the illness, the worse the mental health and medical condition, we should consider it to analyze whether arthritis has an influence on sleep.

\section{Conclusion}

Low vitamin D levels and the presence of arthritis may be associated with the risk of short sleep duration. The association between vitamin $\mathrm{D}$ deficiency and short sleep duration was stronger in individuals with arthritis. Considering that low vitamin D and arthritis are prevalent globally, a strategy to modify these factors to facilitate restorative sleep is needed.

\section{Disclosure}

Sun-Young Kim, Mi Hyun Lee, Weon-Jeong Lim, Soo In Kim, and Yu Jin Lee report no conflicts of interest in this work.

\section{References}

1. Palacios C, Gonzalez L. Is vitamin D deficiency a major global public health problem? J Steroid Biochem Mol Biol. 2014;144:138-145. doi:10.1016/j.jsbmb.2013.11.003

2. Park JH, Hong IY, Chung JW, Choi HS. Vitamin D status in South Korean population: seven-year trend from the KNHANES. Medicine. 2018;97(26):e11032. doi:10.1097/MD.0000000000011032

3. Cassim R, Russell MA, Lodge CJ, Lowe AJ, Koplin JJ, Dharmage SC. The role of circulating 25 hydroxyvitamin D in asthma: a systematic review. Allergy. 2015;70(4):339-354. doi:10.1111/all.12583

4. Chowdhury R, Stevens S, Ward H, Chowdhury S, Sajjad A, Franco OH. Circulating vitamin D, calcium and risk of cerebrovascular disease: a systematic review and meta-analysis. Eur J Epidemiol. 2012;27(8):581-591. doi:10.1007/s10654-012-9729-z

5. Jeon S-M, Shin E-A. Exploring vitamin D metabolism and function in cancer. Exp Mol Med. 2018;50(4):20. doi:10.1038/s12276-018-0038-9

6. Wang J, Lv S, Chen G, et al. Meta-analysis of the association between vitamin D and autoimmune thyroid disease. Nutrients. 2015;7 (4):2485-2498. doi:10.3390/nu7042485

7. Eyles DW, Burne THJ, McGrath JJ, Vitamin D. Effects on brain development, adult brain function and the links between low levels of vitamin D and neuropsychiatric disease. Front Neuroendocrinol. 2013;34(1):47-64. doi:10.1016/j.yfrne.2012.07.001
8. Muscogiuri G, Barrea L, Scannapieco M, et al. The lullaby of the sun: the role of vitamin D in sleep disturbance. Sleep Med. 2019;54:262-265. doi:10.1016/j.sleep.2018.10.033

9. Itani O, Jike M, Watanabe N, Kaneita Y. Short sleep duration and health outcomes: a systematic review, meta-analysis, and meta-regression. Sleep Med. 2017;32:246-256. doi:10.1016/j.sleep.2016.08.006

10. Han KT, Kim DW, Kim SJ. Is sleep duration associated with biological age (BA)?: analysis of (2010-2015) South Korean NHANES dataset South Korea. Int J Environ Res Public Health. 2018;15 (9):2009. doi:10.3390/ijerph15092009

11. Gao Q, Kou T, Zhuang B, Ren Y, Dong X, Wang Q. The association between Vitamin D deficiency and sleep disorders: a systematic review and meta-analysis. Nutrients. 2018;10(10):1395. doi:10.3390/nu1010 1395

12. Mathias JL, Cant ML, Burke ALJ. Sleep disturbances and sleep disorders in adults living with chronic pain: a meta-analysis. Sleep Med. 2018;52:198-210. doi:10.1016/j.sleep.2018.05.023

13. Hong JW, Noh JH, Kim DJ, Kwon YD. The prevalence of and demographic factors associated with radiographic knee osteoarthritis in Korean adults aged $\geq 50$ years: the 2010-2013 Korea national health and nutrition examination survey. PLoS One. 2020;15(3): e0230613. doi:10.1371/journal.pone.0230613

14. Won S, Cho SK, Kim D, et al. Update on the prevalence and incidence of rheumatoid arthritis in Korea and an analysis of medical care and drug utilization. Rheumatol Int. 2018;38(4):649-656. doi:10.1007/s00296-017-3925-9

15. Wu Z, Malihi Z, Stewart AW, Lawes CM, Scragg R. The association between vitamin $\mathrm{D}$ concentration and pain: a systematic review and meta-analysis. Public Health Nutr. 2018;21(11):2022-2037. doi:10.1017/S1368980018000551

16. Wintermeyer E, Ihle C, Ehnert S, et al. Crucial role of vitamin D in the musculoskeletal system. Nutrients. 2016;8(6):319. doi:10.3390/ nu8060319

17. About Korea national health and nutrition examination survey (KNHANES) [homepage on the internet]. South Korea: Korea Centers for Disease Control and Prevention (KCDC); 2020. Available from: https://knhanes.cdc.go.kr/knhanes/eng/index.do. Accessed Apr 2, 2020.

18. Jung IK. Prevalence of vitamin D deficiency in Korea: results from KNHANES 2010 to 2011. J Nutr Health. 2013;46(6):540-551. doi:10.4163/jnh.2013.46.6.540

19. Thacher TD, Clarke BL. Vitamin D insufficiency. Mayo Clin Proc. 2011;86(1):50-60. doi:10.4065/mcp.2010.0567

20. Watson NF, Badr MS, Belenky G, et al. Joint consensus statement of the American academy of sleep medicine and sleep research society on the recommended amount of sleep for a healthy adult: methodology and discussion. J Clin Sleep Med. 2015;11(8):931-952. doi: $10.5664 /$ jcsm. 4950

21. Guidelines for the data processing and analysis of the international physical activity questionnaire (IPAQ) [homepage on the internet]. USA: The IPAQ group; 2011. Available from: http://www.ipaq.ki.se. Accessed Sep 2, 2020.

22. Guglielmo D, Murphy LB, Boring MA, et al. State-specific severe joint pain and physical inactivity among adults with arthritis-United States, 2017. MMWR Morb Mortal Wkly Rep. 2019;68(17):381-387. doi:10.15585/mmwr.mm6817a2

23. Savastano S, Barrea L, Savanelli MC, et al. Low vitamin D status and obesity: role of nutritionist. Rev Endocr Metab Disord. 2017;18 (2):215-225. doi:10.1007/s11154-017-9410-7

24. Liu Y, Hazlewood GS, Kaplan GG, Eksteen B, Barnabe C. Impact of obesity on remission and disease activity in rheumatoid arthritis: a systematic review and meta-analysis. Arthritis Care Res (Hoboken). 2017;69(2):157-165. doi:10.1002/acr.22932

25. Wang T, He C. Pro-inflammatory cytokines: the link between obesity and osteoarthritis. Cytokine Growth Factor Rev. 2018;44:38-50. doi:10.1016/j.cytogfr.2018.10.002 
26. Hirshkowitz M, Whiton K, Albert SM, et al. National sleep foundation's updated sleep duration recommendations. Sleep Health. 2015;1 (4):233-243. doi:10.1016/j.sleh.2015.10.004

27. Liu X, Baylin A, Levy PD. Vitamin D deficiency and insufficiency among US adults: prevalence, predictors and clinical implications. $\mathrm{Br}$ J Nutr. 2018;119(8):928-936. doi:10.1017/S0007114518000491

28. Bertisch SM, Sillau S, de Boer IH, Szklo M, Redline S. 25Hydroxyvitamin D concentration and sleep duration and continuity: multi-ethnic study of atherosclerosis. Sleep. 2015;38(8):1305-1311. doi: $10.5665 /$ sleep. 4914

29. Eyles DW, Smith S, Kinobe R, Hewison M, McGrath JJ. Distribution of the vitamin D receptor and 1 alpha-hydroxylase in human brain. J Chem Neuroanat. 2005;29(1):21-30. doi:10.1016/j.jchemneu.2004.08.006

30. Muzur A, Pace-Schott EF, Hobson JA. The prefrontal cortex in sleep. Trends Cogn Sci. 2002;6(11):475-481. doi:10.1016/S1364-6613(02) 01992-7

31. Iranzo A, Lomeña F, Stockner H, et al. Decreased striatal dopamine transporter uptake and substantia nigra hyperechogenicity as risk markers of synucleinopathy in patients with idiopathic rapid-eyemovement sleep behaviour disorder: a prospective study. Lancet Neurol. 2010;9(11):1070-1077. doi:10.1016/S1474-4422(10)70216-7

32. McKinley MJ, Yao ST, Uschakov A, McAllen RM, Rundgren M, Martelli D. The median preoptic nucleus: front and centre for the regulation of body fluid, sodium, temperature, sleep and cardiovascular homeostasis. Acta Physiol. 2015;214(1):8-32.

33. Lu J, Greco MA, Shiromani P, Saper CB. Effect of lesions of the ventrolateral preoptic nucleus on NREM and REM sleep. $J$ Neurosci. 2000;20(10):3830-3842. doi:10.1523/JNEUROSCI.20-10-03830.2000
34. Sassi F, Tamone C, D'Amelio P. Vitamin D: nutrient, hormone, and immunomodulator. Nutrients. 2018;10(11):1656. doi:10.3390/ nu10111656

35. Dantzer R, O'Connor JC, Freund GG, Johnson RW, Kelley KW. From inflammation to sickness and depression: when the immune system subjugates the brain. Nat Rev Neurosci. 2008;9(1):46-56. doi:10.1038/nrn2297

36. Patrick RP, Ames BN. Vitamin D hormone regulates serotonin synthesis. Part 1: relevance for autism. FASEB J. 2014;28(6):2398-2413. doi:10.1096/fj.13-246546

37. Dauvilliers Y, Evangelista E, Lopez R, et al. Vitamin D deficiency in type 1 narcolepsy: a reappraisal. Sleep Med. 2017;29:1-6. doi:10. 1016/j.sleep.2016.05.008

38. Neighbors CLP, Noller MW, Song SA, et al. Vitamin D and obstructive sleep apnea: a systematic review and meta-analysis. Sleep Med. 2018;43:100-108. doi:10.1016/j.sleep.2017.10.016

39. McCarty DE, Reddy A, Keigley Q, Kim PY, Marino AA. Race, and excessive daytime sleepiness. J Clin Sleep Med. 2012;8(6):693-697. doi:10.5664/jcsm.2266

40. Kim JH, Park EC, Lee KS, et al. Association of sleep duration with rheumatoid arthritis in Korean adults: analysis of seven years of aggregated data from the Korea national health and nutrition examination survey (KNHANES). BMJ Open. 2016;6(12):e011420. doi:10.1136/bmjopen-2016-011420

41. Jung JH, Seok H, Choi SJ, et al. The association between osteoarthritis and sleep duration in Koreans: a nationwide cross-sectional observational study. Clin Rheumatol. 2018;37(6):1653-1659. doi:10.1007/s10067-018-4040-3

\section{Publish your work in this journal}

Nature and Science of Sleep is an international, peer-reviewed, open access journal covering all aspects of sleep science and sleep medicine, including the neurophysiology and functions of sleep, the genetics of sleep, sleep and society, biological rhythms, dreaming, sleep disorders and therapy, and strategies to optimize healthy sleep.
The manuscript management system is completely online and includes a very quick and fair peer-review system, which is all easy to use. Visit http://www.dovepress.com/testimonials.php to read real quotes from published authors. 